EESTI NSV TEADUSTE AKADEEMIA TOIMETISED. FUOSIKA * MATEMAATIKA

ИЗВЕСТИЯ АКАДЕМИИ НАУК ЭСТОНСКОП ССР. ФИЗИКА * МАТЕМАТИКА

PROCEEDINGS OF THE ACADEMY OF SCIENCES OF THE ESTONIAN SSR.

PHYSICS * MATHEMATICS

1984, 33, 1

удк 621.382

Г. АШКИНАЗИ, О. ЗОЛОТАРЕВСКАЯ, Л. МАЗО,

А. ПАДЬЮС, К. СТЕПАНОВ, М. СЫРКИНА

\title{
ИССЛЕДОВАНИЕ ВЗАИМОДЕЙСТВИЯ АРСЕНИДА ГАЛЛИЯ С ОРГАНОСИЛИКАТНЫМИ ПОКРЫТИЯМИ И ВЛИЯНИЯ ЭТИХ ПОКРЫТИЙ НА ОБРАТНУЮ ВЕТВЬ ВАХ СиловЫХ диОдов
}

Создание силовых полупроводниковых приборов на основе арсенида галлия выдвигает дополнительные требования к пассивирующим и защитным материалам. Прежде всего - повышенная термостойкость защитных материалов, ввиду более высокой рабочей температуры $\left(\sim 30{ }^{\circ} \mathrm{C}\right)$ арсенид-галлиевых приборов. Наряду с высокой термостойкостью, защитное покрытие должно обладать и достаточной эластичностью, чтобы не надо было согласовывать коэффициенты термического линейного расширения покрытия и структуры. Все широко распространенные и доступные полимерные материалы, обладающие хорошей эластичностью, не являются достаточно термостойкими. Неорганические материалы, как стекло и керамика являются термостойкими, но не обладают достаточной эластичностью. Кроме того, технология нанесения таких материалов на поверхность полупроводниковых приборов связана обычно с высокими температурами, что ограничивает, а в некоторых случаях делает вообще неприемлемым использование таких покрытий в силу низкой температуры декомпозиции самого арсенида галлия.

В этом плане представляют интерес органосиликатные композиции типа: полиметилфенилсилоксан-силикат-окисел.

Ранее было показано $\left[{ }^{1}\right]$, что эти материалы являются достаточно эффективными для защиты силовых приборов на основе арсенида галлия. Поэтому были продолжены работы по исследованию термических и электрофизических свойств этих покрытий с целью обеспечения стабильной и надежной работы силовых приборов на основе арсенида галлия.

\section{1. Исследование взаимодействия органосиликатных покрытий с арсенидом галлия}

Как известно, формирование гетерогенных полимерных композиционных материалов в значительной мере определяется спецификой процессов взаимодействия между компонентами. Особенностью контактного и граничного взаимодействия системы покрытие-подложка является протекание контактных химических реакций, на ход которых существенное влияние оказывают поверхностные соединения компонентов, а также контактное химическое окисление. Установление определенных закономерностей этих явлений расширяет представление о механизме формирования композиционных материалов, их строении, дает возможность прогнозировать свойства этих материалов. 


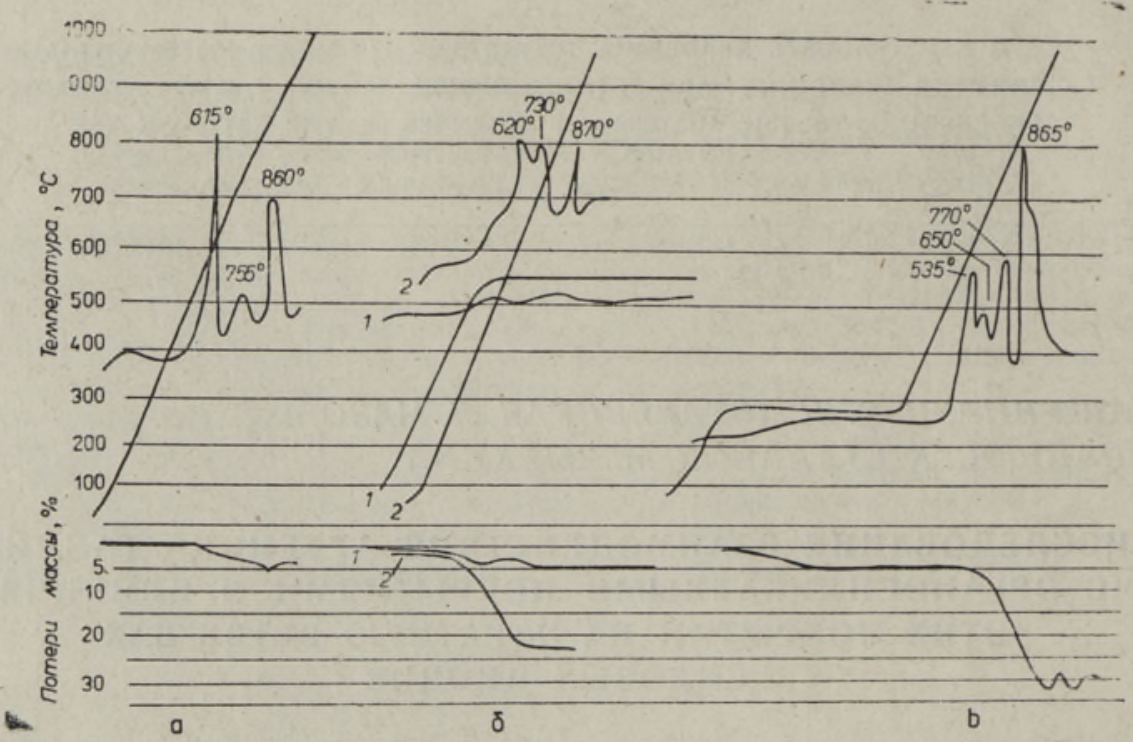

Рис. 1. Дериватограммы арсенида галлия $(a)(G-910$ мг, $T G-500$ мг, ДТА $-1 / 5, V_{\text {н }}-5$ град/мин, $T-1000^{\circ}$ ), исходного покрытия (б) $\left(G-455, T G-500 \mathrm{мr}\right.$, ДТА $-1 / 5 ; 1-V_{\mathrm{H}}-2,5$ град/мин, $T-270^{\circ}$, время -3 ч; $2-V_{\text {н }}-5$ град/мин, $T-1000^{\circ}$ ) и смеси арсенида галлия с покрытием $(в)\left(G_{\text {покрытн }}-455, G_{\mathrm{GaAs}}-455 \mathrm{мr}, T-500 \mathrm{мr}\right.$, ДТА $-1 / 5$, $V_{\text {н }}-2,5$ град/мин, $T_{1}-270^{\circ}$, время -3 ч, $V_{\text {н }}-5$ град/мин. $\left.T_{2}-1000^{\circ} \mathrm{C}\right)$.

$\mathrm{K}$ гетерогенным реакциям относится и взаимодействие арсенида галлия с компонентами покрытия. Органосиликатные материалы являются достаточно инертными, даже при повышенных температурах. Заметное взаимодействие компонентов покрытия начинается при температурах $\sim 600^{\circ}$. Однако возможно снижение этой температуры с помощью катализаторов, которыми могут быть окислы, входящие в покрытие, наложением электрического поля, временным воздействием. Поэтому не исключено, что взаимодействие покрытия с поверхностью арсенида галлия будет происходить при работе приборов, а это может сказываться на его характеристиках. Следует отметить, что изучение подобного рода покрытий крайне затруднено из-за сложности (многокомпонентности) изучаемой системы. Поэтому выводы о химическом взаимодействии можно делать лишь в общем виде (смещение пиков, изменение абсолютных значений тепловых эффектов, изменение величины и скорости деструкции).

Опыты проводились методом дифференциально-термического (ДТА) и термо-гравиметрического анализа (ТГА) на дериватографе системы «Паулик, Паулик, Эрдеи». В качестве органосиликатного материала была выбрана композиция на основе разветвленного полиметилфенилсилоксана с наполнителем - асбестом. В композицию вводились следующие окислы: $\mathrm{Cr}_{2} \mathrm{O}_{3}, \mathrm{TiO}_{2}, \mathrm{NiO}, \mathrm{WO}_{3}, \mathrm{~V}_{2} \mathrm{O}_{5}$.

Тщательно перемешанный с арсенидом галлия органосиликатный материал в соотношении $1: 1$ отверждался по следующему режиму: нагрев со скоростью 2,5 град/мин до $270^{\circ}$ и выдержка при этой температуре в течение 3 ч. Затем отвержденная смесь нагревалась со скоростью 5 град/мин до $1000^{\circ}$. По полученным дериватограммам определялась температура, направление и величина тепловых эффектов $\left[{ }^{2}\right]$, потеря массы и энергия активации $\left[{ }^{3}\right]$ протекающих процессов.

При рассмотрении дериватограммы чистого арсенида галлия (рис. $1, a$ ) можно видеть, что нагрев образца приводит к появлению на кривой ДТА трех экзотермических пиков при 615,755 и $860^{\circ}$. Можно 
предположить, что интенсивное выделение тепла при $615^{\circ}$ связано с термическим-разложением арсенида галлия: уходом $\mathrm{As}_{2}$ (г) и присоединением кислорода с образованием $\mathrm{Ga}_{2} \mathrm{O}_{3}$ по реакции:

$$
2 \mathrm{GaAs}+3 / 2 \mathrm{O}_{2} \rightarrow \mathrm{Ga}_{2} \mathrm{O}_{3}+\mathrm{As}_{2} .
$$

Это подтверждают данные потери массы образца в интервале температур $580-650^{\circ}$ и совпадение величины измеренного по дериватограммам теплового эффекта (58 Дж/г) с рассчитанным обычным термодинамическим путем (53,8 Дж/г).

При температуре второго экзотермического эффекта $755^{\circ}$ происходит замедление потерь массы из-за затрудненности диффузии через образовавшуюся пленку $\mathrm{Ga}_{2} \mathrm{O}_{3}$ из глубины зерна. Экзоэффект, очевидно, обусловлен началом процесса кристаллизации аморфной пленки. При $860^{\circ}$ после незначительных потерь $(0,8 \%)$ начинауется интенсивное увеличение массы, что, очевидно, можно объяснить присоединением кислорода не только к галлию, но и к мышьяку с образованием ортоарсената галлия $\mathrm{GaAsO}_{4}\left[{ }^{4}\right]$. Низкая величина энергии активации первой стадии (63 кДж/моль) свидетельствует о протекании процесса в диффузионной области. Увеличение энергии активации на второй и третьей стадиях до 168 и 289 кДж/моль соответственно подтверждает положение о том, что в связи с кристаллизацией снимаются диффузионные торможения и процесс переходит в кинетическую область.

На кривой ДТА покрытия (рис. 1, б) имеются три экзотермических пика. Экзоэффект при температуре $620^{\circ}$ вызывается термоокислением органического обрамления полиорганосилоксана $\left[{ }^{5}\right]$, а при $730^{\circ}$, очевидно, связан с образованием керамической структуры без изменения массы. При $870^{\circ}$ появляется экзотермический эффект, который вызывается распадом кристаллической решетки асбеста и переходом его в новую фазу с образованием форстерита [ $\left.{ }^{6}\right]$.

При сравнении дериватограмм отдельных компонентов можно видеть, что экзотермические эффекты арсенида галлия и покрытия совпадают по температурам, но имеют различные величины (таблица). При совместном испытании покрытия с арсенидом галлия (рис. 1,8 ) происходит смещение температур экзотермических эффектов в сторону более высоких температур, что свидетельствует о химическом взаимодействии $\left[{ }^{7}\right]$. Величина теплового эффекта при $650^{\circ}$ снижается до 5 Дж/г, что говорит о подавлении процесса окисления. Однако деструкция образца несколько увеличивается (равна сумме потерь массы двух исследуемых компонентов). Тепловой эффект в области $730-750^{\circ}$ примерно равен суммарному тепловому эффекту, однако потери массы можно отнести в основном за счет покрытия. И, наконец, взаимодействие арсенида галлия и покрытия приводит к значительному увеличению теплового эффекта при $865^{\circ}$, что, очевидно, говорит о некотором инициировании процесса окисления арсенида галлия.

\begin{tabular}{l|c|c|c}
\hline Композиция & $\begin{array}{c}\text { Tемпера- } \\
\text { тура тепло- } \\
\text { вого эффек- } \\
\text { та, }{ }^{\circ} \mathrm{C}\end{array}$ & $\begin{array}{c}\text { Величина } \\
\text { теплового } \\
\text { эффекта, } \\
\text { Дж/r }\end{array}$ & $\begin{array}{c}\text { Потери } \\
\text { массы, } \\
\text { от массы } \\
\text { образца }\end{array}$ \\
\hline & 615 & 58 & 1,65 \\
Арсенид галлия & 755 & 18 & 2,25 \\
Покрытие & 860 & 45 & 3,30 \\
& 620 & 34 & 9,89 \\
Покрытие на & 730 & 16 & 22,53 \\
GaAs & 870 & 22 & 23,63 \\
& 650 & 5 & 6,59 \\
& 770 & 39 & 11,26 \\
\end{tabular}




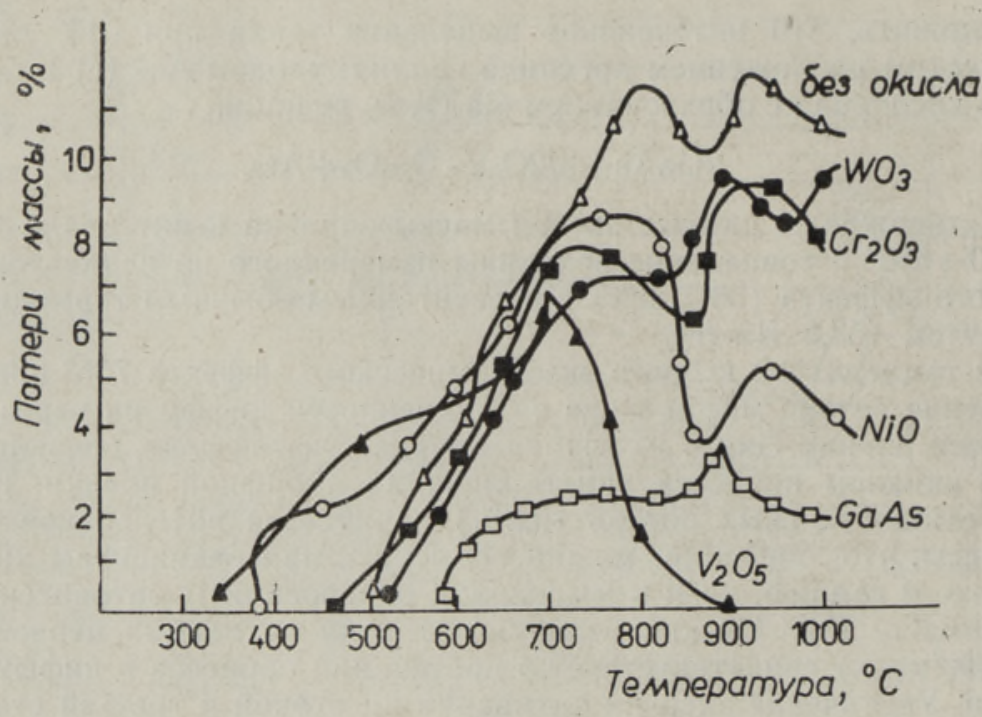

Рис. 2. Влияние различных окислов, введенных в состав ОСМ, на потери массы композиции; покрытие - арсенид галлия.

При смешении арсенида галлия с покрытием характер кривой потерь массы меняется. У чистого арсенида галлия наблюдается острый пик потери массы при $870^{\circ}$, затем начинается прирост ее вследствие присоединения кислорода. При введении покрытия появляются два максимума потери массы (ниже 800 и $\sim 900^{\circ}$ ). Очевидно, это связано с изменением морфологии и фазового состава композиции полиорганосилоксан-хризотиловый асбест-окисел. При $800^{\circ}$ начинается образование зернистой структуры, которое завершается к $1000^{\circ}$. Вероятно, поведение арсенида галлия связано с изменением диффузионных факторов и, следовательно, с различной скоростью проникновения кислорода вглубь зерна.

При рассмотрении влияния различных окислов в составе органосиликатного материала (ОСM) на потери массы (рис. 2) можно видеть, что введение всех вышеуказанных окислов снижает суммарные потери массы композиции арсенид галлия - покрытие. При этом $\mathrm{Cr}_{2} \mathrm{O}_{3}$ и $\mathrm{NiO}$ сдвигают максимум потерь массы в область более низких температур, а $\mathrm{WO}_{3}$ повышает эту температуру, что, вероятно, связано со стойкостью связи $\mathrm{Si}-\mathrm{C}$ к окислу.

Совершенно иная картина наблюдается при нагревании арсенида галлия с покрытием, содержащим $\mathrm{V}_{2} \mathrm{O}_{5}$. В этом случае на кривой потерь массы имеется один максимум при температуре $700^{\circ}$, а затем начинается интенсивное присоединение кислорода. Очевидно, $\mathrm{V}_{2} \mathrm{O}_{5}$ оказывает каталитическое действие при окислении арсенида галлия.

Таким образом, сопоставление характера дериватограмм чистого покрытия и арсенида галлия показывает, что при нагревании в них протекают близкие по термохимическим параметрам превращения - термоокислительная деструкция и термическая диссоциация. Совпадение температурных максимумов тепловых эффектов свидетельствует о хорошей совместимости покрытия и подложки.

Сдвиг температуры максимальных экзоэффектов в более высокотемпературную область и изменение величин тепловых эффектов свидетельствуют о химическом взаимодействии арсенида галлия и покрытия, которое происходит, однако, при температурах выше $600^{\circ}$. 


\section{๘. Исследование влияния защитных покрытий на обратную ветвь ВАХ арсенид-галлиевых силовых диодов}

В качестве объекта исследования были выбраны органосиликатные композиции ВНВ-2, ВНТ-45/8, ВНТ-56/1 и обладающий повышенной термостойкостью $\left[{ }^{8}\right]$ по сравнению с кремнийорганическими компаундами, применяемыми для защиты силовых приборов на основе кремния, модифицированный кремнийорганический эластомер «Лестосил». Для сравнения были исследованы КЛТ-30 и «Эластосил», широко используемые для защиты силовых кремниевых приборов.

Изучение влияния различных покрытий на обратную ветвь ВАХ арсенид-галлиевых приборов проводили путем последовательного нанесения и снятия исследуемых покрытий на одни и те же структуры. Это позволяет при сохранении объемных свойств выявить влияние собственно защитных покрытий на обратную ветвь BAX приборов. Измерения обратной ветви ВАХ проводились последовательно после химической обработки, перед нанесением защитных покрытий, затем после отверждения покрытий и после высокотемпературной обработки $\left(T=380^{\circ}\right.$, время 10 мин), имитирующей процесс пайки в корпус.

Химическая обработка боковой поверхности арсенид-галлиевых приборов перед нанесением покрытий проводилась в травителе $3: 1: 1=$ $=\mathrm{H}_{2} \mathrm{SO}_{4}: \mathrm{H}_{2} \mathrm{O}_{2}: \mathrm{H}_{2} \mathrm{O}$.

Отверждение покрытий проводили по следующим режимам:

ВНТ-45/8, ВНТ-56/1 и ВНВ-2 при $T=260-280^{\circ}$ в течение 3 ч;

«Лестосил» при $T=25^{\circ}$ в течение 12 ч, при $T=80^{\circ}$ в течение $3-4$ ч и при $T=260-280^{\circ}$ в течение 3 ч;

КЛТ-30 при $T=25^{\circ}$ в течение 18 ч, при $T=160-180^{\circ}$ в течение 5 ч;

«Эластосил» при $T=25^{\circ}$ в течение 12 ч, при $T=80^{\circ}$ в течение $3-4$ ч и при $T=160-180^{\circ}$ в течение 5 ч.

Как показали проведенные исследования, снятие герметизирующих покрытий на основе кремнийорганических полимеров путем кипячения (30 мин) в $10 \%$-ном растворе $\mathrm{KOH}$ не повреждает поверхности приборов на основе арсенида галлия. Нейтрализация $\mathrm{KOH}$ проводилась в $\mathrm{HF}: \mathrm{H}_{2} \mathrm{O}=1: 1$. Для возвращения поверхности приборов в исходное состояние перед каждым новым нанесением покрытия проводилось освежение поверхности в травителе $3: 1: 1=\mathrm{H}_{2} \mathrm{SO}_{4}: \mathrm{H}_{2} \mathrm{O}_{2}: \mathrm{H}_{2} \mathrm{O}$.

Результаты измерений после нанесения и отверждения различных покрытий представлены в виде усредненных характеристик (рис. 3). Как видно из рис. 3 защитные покрытия ВНТ-45/8, «Лестосил», ВНТ-56/1 и ВНВ-2 не изменяют вида обратной ветви, заданной процессом травления. Уровень обратного тока при этом или практически совпадает (ВНТ-45/8, «Лестосил») с уровнем тока после травления, или несколько выше (ВНТ-56/1 и ВНВ-2). Защитные покрытия, используемые для герметизации кремниевых приборов (КЛТ-30 и «Эластосил»), несколько изменяют вид обратной ветви ВАХ в области высоких напряжений, где скорость роста тока увеличивается. Существенные различия в виде обратной ветви ВАХ проявляются после высокотемпературной обработки, имитирующей процесс пайки в корпусе (рис. 4). Обратный ток увеличивается у всех структур, защищенных исследуемыми покрытиями (ВНТ-45/8 и «Лестосил» - слабо, ВНВ-2 и ВНТ-56/1 - заметно), при этом вид обратной ветви ВАХ, заданный процессом травления, практически не меняется. Что касается покрытий КЛТ-30 и «Эластосил», то они не только значительно увеличивают обратный ток при малых напряжениях, но и существенно увеличивают скорость роста тока с напряжением, изменяя вид обратной ветви BAX.

Из анализа обратной ветви ВАХ, приведенных на рис. 3 и 4 следует, что наиболее перспективными для защиты силовых полупроводниковых 


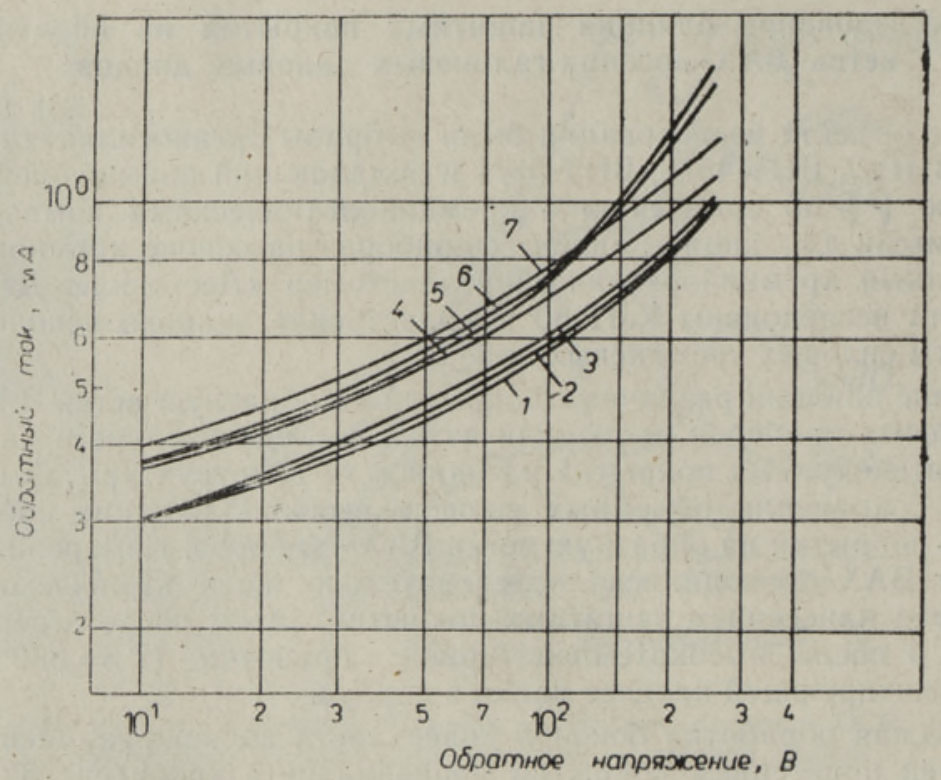

Рис. 3. Обратная ветвь ВАХ арсенид-галлиевых структур с различными защитными покрытиями, измеренные при температуре $260^{\circ}: 1$ - незащищенные структуры, 2 - ВНТ-45/8, 3 - «Лестоснл», 4 - ВНТ-56/1, 5 - «Эластосил», 6 - КЛТ-30, 7 - ВНВ-2.

приборов на основе арсенида галлия являются покрытия ВНТ-45/8 и «Лестосил».

Известно, что режим отверждения покрытия оказывает существенное влияние на качество самого покрытия, на его физико-химические и электрические свойства. Был опробован ряд режимов отверждения композиции КЛТ-30. При отверждении по режимам $T=25^{\circ}, 18$ ч и $T=260$ $280^{\circ}, 3$ ч было отмечено значительное понижение обратного тока (рис. 5 ). Вероятно, повышение температуры термообработки способствует более полному отверждению КЛТ-30, удалению низкомолекулярных продуктов

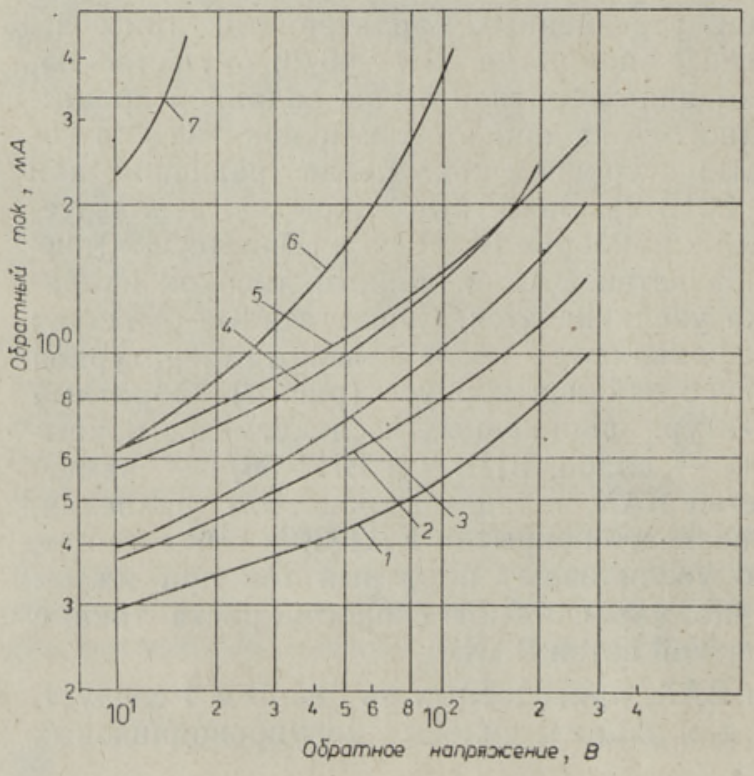

и стабилизации свойств границы раздела арсенид галлия - покрытие. При этом покрытие КЛТ-30 по своему влиянию на обратную ветвь ВАХ после отверждения и высокотемпературной обработки стало срапнимо с «Лестосилом».

Рис. 4. Обратная ветвь ВАХ арсенид-галлиевых структур с различными защитными покрытиями после высокотемпературной обработки $\left(380^{\circ}\right)$, измеренные при температуре $260^{\circ}$ : I - незащищенные структуры, 2 - ВНТ-45/8, 3 - «Лестосил», 4 - ВНТ-56/1, 5 ВНВ-2, 6 - КЛТ-30, 7 «Эластосил». 
Рис. 5. Обратная ветвь ВАХ арсенидгаллиевых структур с различными защитными покрытиями, измеренные при - температуре $260^{\circ}: 1-$ незащищенные структуры, 2 - КЛТ-30 $\left(T_{\text {отв }}=260-280^{\circ}\right) ;$ после высокотемпературной обработки $T=380^{\circ}$; 3 - ВНТ-45/8, 4 - «Лестосил», 5 - КЛТ-30 $\left(T_{\text {отв }}=260-280^{\circ}\right)$.

Таким образом, герметизирующие защитные покрытия, применяемые для защиты кремниевых приборов, не пригодны для защиты силовых приборов на основе арсенида галлия. Однако в некоторых случаях подбором режима отверждения этих покрытий, модификацией состава и т. п.

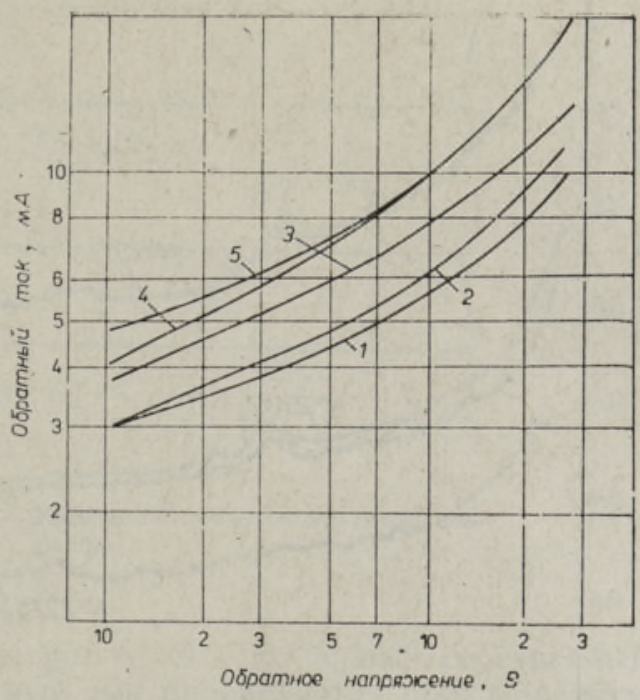
можно значительно их улучшить и использовать для защиты арсенид-галлиевых приборов. Наиболее перспективными в этом отношении являются покрытия на основе кремнийорганических полимеров - ВНТ-

\section{3. Исследование стабильности обратной ветви ВАХ арсенид-галлиевых диодов}

Неизменность основных электрических параметров полупроводникового прибора во времени, т. е. его стабильность, во многом определяет возможность использования данного прибора в различных областях техники. Прибор с высокими, но нестабильными параметрами может найти только ограниченное применение. Это определяет необходимость исследования стабильности обратной ветви ВАХ арсенид-галлиевых при-
боров.

Объектом исследования служили диодные структуры арсенид-галлиевых силовых приборов диаметром 6,7 мм, изготовленные в лабораторных условиях. Боковая поверхность структур была защищена после травления покрытиями типа ВНТ. Затем структуры были разделены на две части. Первая группа приборов была выдержана при $260^{\circ}$ в течение 100 ч без приложения обратного напряжения. Вторая группа испытывалась в тех же условиях, но с приложением обратного напряжения $(150$ В). У диодов второй группы во время испытаний непрерывно регистрировалась с помощью многоточечного потенциометра величина обратного тока. На всех диодах до и после испытаний были измерены следующие параметры: величина времени жизни неосновных носителей заряда, вольт-емкостные характеристики и параметры обратной ветви BAX при 20 и $260^{\circ}$. Испытания проводились в два этапа. Сначала структуры были испытаны без термообработки, а затем те же структуры, подвергнутые термообработке при $380^{\circ}$ в течение 10 мин.

Типичные кривые изменения обратного тока во времени для второй группы структур приведены на рис. 6, откуда видно, что обратный ток уменьшается во времени в течение $\sim 80$ ч. Уменьшение обратного тока наблюдается как на структурах, прошедших термообработку, так и на структурах, не прошедших ее. Эти изменения наглядно видны также при замерах обратной ветви ВАХ при $260^{\circ}$ (см. рис. 7). После испытания на стабильность обратный ток уменьшается почти в два раза (кривая 2) по сравнению с начальным значением (кривая 1). Последующая тер- 


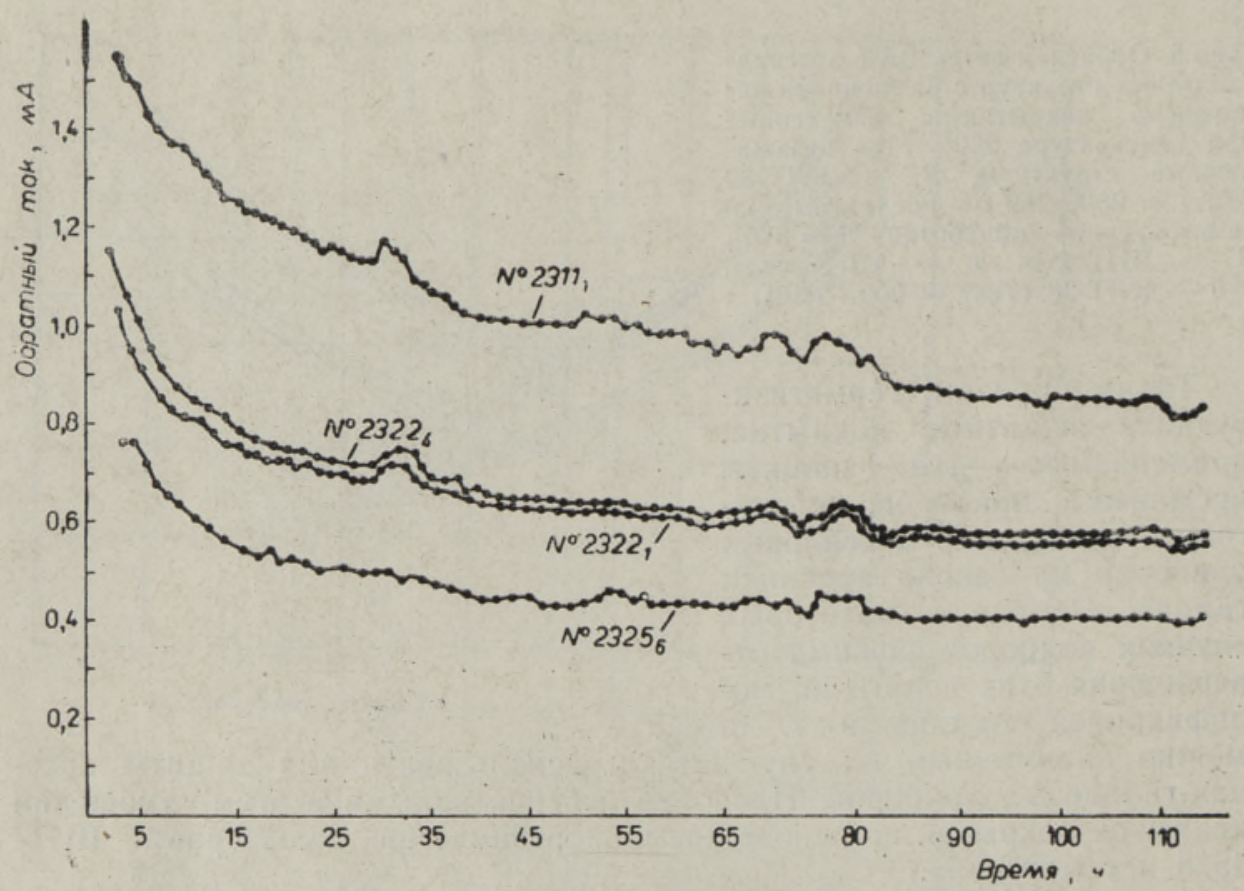

Рис. 6. Динамика изменения обратного тока при испытании на стабильность с приложением обратного напряжения.

мообработка при $380^{\circ}$ приводит к увеличению обратного тока (кривая 3 ), а последующая выдержка при $260^{\circ}$ с приложением обратного напряжения (испытание на стабильность) приводит снова к уменьшению обратного тока (кривая 4).

Иная картина наблюдается у диодов первой группы, которые были выдержаны при $260^{\circ}$ без приложения обратного напряжения. В этом случае обратная ветвь ВАХ структур, не прошедших термообработку, не меняется, а термообработанные структуры изменяют свои характеристики более слабо и изменения носят случайный характер. Вольт-емкостные характеристики и времена жизни неосновных носителей заряда не изменили своих значений во время испытаний, как в первой, так и во второй группе. Также не изменилась величина напряжения пробоя структур при $20^{\circ}$.

Из рис. 7 можно также видеть, что уменьшение обратного тока для структур второй группы наблюдается уже при $10 \mathrm{~B}$, хотя испытуемые структуры имели напряжение пробоя около 300 В. Поэтому эффект уменьшения обратного тока не связан с про-

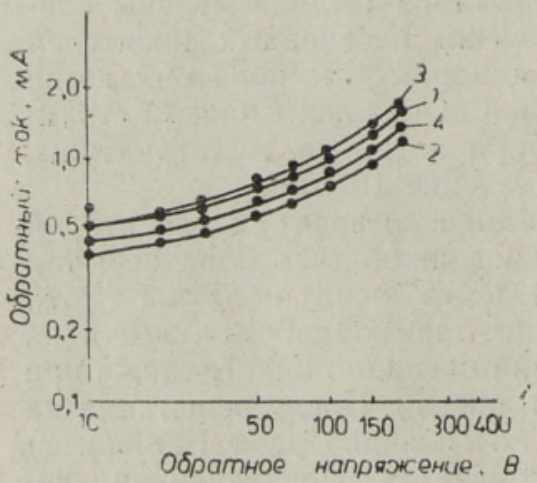
бойными явлениями. Природу этого явления можно объяснить изменениями в генерационных процессах в слое объемного заряда. При этом в структу-

Рис. 7. Типичные обратные ветви ВАХ структур (при $260^{\circ}$ ): $I$ - перед испытанием на стабильность, 2 - после испытания на стабильность с приложением напряжения, 3 - после высокотемпературной термообработки, 4 - после второго испытания на стабнльность. 


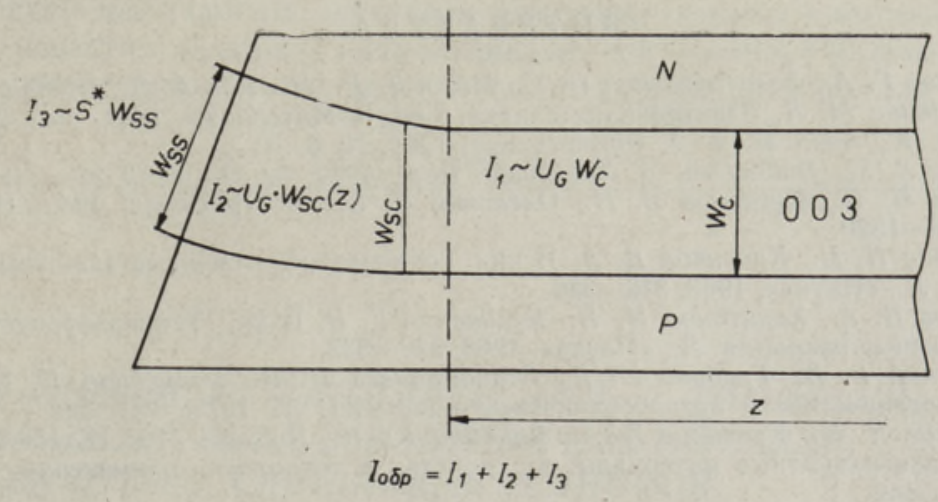

Рис. 8. Қачественная модель составляющих обратного тока силового диода.

ре можно выделить три области (см. рис. 8). Это, во-первых, собственный объем полупроводника, где обратный ток определяется произведением скорости объемной генерации $\left(U_{G}\right)$ и ширины области объемного заряда $\left(W_{C}\right)$ в полупроводнике, во-вторых, приповерхностный слой объемного заряда, где скорость генерации носителей заряда соответствует объемной $\left(U_{G}\right)$, но ширина области объемного заряда $\left(W_{S C}(Z)\right)$ меняется в зависимости от угла «фаски» и заряда на поверхности и, в-третьих, собственно поверхность, где темп генерации определяется неравновесной скоростью поверхностной рекомбинации $\left(S^{*}\right)\left[{ }^{9}\right]$ и шириной области объемного заряда (OO3) на поверхности $\left(W_{S S}\right)$. В случае такой геометрии структур, где $I_{2} \ll I_{1}$, величину $I_{2}$ можно не учитывать. Так как вольт-емкостные характеристики диодов не изменялись во время испытаний, а емкость диода является функцией от ширины области объемного заряда $\left(W_{C}\right)$, то $I_{1}$ не должна изменяться во время испытаний. Поэтому можно предположить, что изменение обратного тока связано с изменением компоненты $I_{3}$. В свою очередь изменение $I_{3}$ может быть связано с изменением либо $S^{*}$, либо $W_{S S}$.

Проведенные нами исследования, а также данные $\left[{ }^{10}\right]$ дают основание предполагать, что пробой арсенид-галлиевых приборов происходит, по-видимому, через поверхность. В таком случае изменение величины $W_{\text {Ss }}$ влияло бы на величину напряжения пробоя. Однако это не происходит и поэтому можно предположить, что изменение $I_{3}$ связано с изменением неравновесной скорости поверхностной рекомбинации $\left(S^{*}\right)$. В этом случае очевидно, что изменение не должно отражаться как на вольт-емкостных характеристиках, так и на напряжении пробоя. Изменение $S^{*}$ также не должно отражаться на величине времени жизни неосновных носителей заряда, так как оно замерено в нейтральных базовых областях, а $S^{*}$ относится к заряженной неравновесной ООЗ. Поэтому вероятной причиной уменьшения обратных токов во время испытания диодных структур на стабильность обратной ветви ВАХ можно считать уменьшение $S^{*}$, что в свою очередь связано с изменением зарядного состояния на поверхности $P-N$-перехода под действием обратного напряжения.

Таким образом, наиболее перспективными для защиты силовых приборов на основе арсенида галлия являются покрытия на основе полиметилфенилсилоксана (ВНТ-45/8) и «Лестосил». При рабочих температурах арсенид-галлиевого диода не наблюдается взаимодействия компонентов покрытия с арсенидом галлия. Вышеуказанные покрытия обеспечивают низкий уровень обратных токов и стабильную работу приборов во времени. 
1. Аикинази Г. А., Золотаревская О. Е., Мазо Л. Д., Падьюс А. Л., Степанов К. Н., Сыркина М. Л. Электронная техника. Сер. 6. Материалы, 1981, вып. 2, 69-72.

2. Tang, B. K., Neill, W. K. J. Polymer Sci., 1964, № 6, 6.3.

3. Zivcovic, Z. D., Dobovisek, B. Thermoch. Acta, 1970, 32, № 1-2, 205-211.

4. Сорокин И. Н., Кузнецов В. Н., Олевский С. С. Электрохнмия, 1982, 18, № 10, $1316-1320$.

5. Харитонов Н. П., Кротиков В. А. В кн.: Температуроустойчивые защитные покрытия. Л., «Наука», 1968, 316-326.

6. Кротиков В. А., Харитонов Н. П., Белинская Г. В. В кн.: Температуроустойчивые защитные покрытия. Л., «Наука», 1968, 326-333.

7. Островский В. В., Глебова И. Б., Стародубщева Н. Н., Харитонов Н. П. В кн.: Неорганические и органоснликатные покрытия. Л., 1975, 360-363.

8. Харитонов Н. П., Кротиков В. А., Худобин Ю. И., Буслаев Г. С., Степанов К. Н. Органосиликатные материалы, их свойства и технология применения. Л., 1979, $137-146$.

9. Литвинов $P$. О. Влияние поверхности на характеристики полупроводниковых приборов. Киев, «Наукова думка», 1972.

10. Алферов Ж. И., Береман Я. В., Корольков В. И., Никитин В. Г., Старкова А. А., Степанова М. Н., Третьяков Д. Н. ФТП, 1977, 11, № 5, 892-898.

Научно-исследовательский институт

Таллинского электротехнического

завода им. М. И. Калинина

G. ASKINAZI, O. ZOLOTAREVSKAJA, L. MAZO,

A. PADJUS, K. STEPANOV, M. SORKINA

\section{GALLIUMARSENIIDI JA ORGANOSILIKAADIST KAITSEMATERJALIDE VASTASTIKUNE MÕJU NING NENDE MATERJALIDE TOIME JOUDIOODIDE - VASTUKARAKTERISTIKUTELE}

DTA- ja TGA-meetodiga on uuritud galliumarseniidi, ja organosilikaadist kaitsematerjalide omavahelist mōju ja leitud, et gailiumarseniidist dioodide töötemperatuuridel ei esine vastastikust mōju galliumarseniidi ja kaitsematerjalide komponentide vahel.

Galliumarseniidist dioodide vastukarakteristiku ja tema stabiilsuse uurimine näitas, et organosilikaadist kompositsioonid BHT-45/8 ja «Лестоснл» tagavad kõige väiksemad vastuvoolud ning vastukarakteristikute stabiilsuse ajas.

G. ASHKINAZI, O. ZOLOTAREVSKAYA, L. MAZO,

A. PADJUS, K. STEPANOV, M. SYRKINA

\section{INVESTIGATIONS OF THE INTERACTION BETWEEN GALLIUM ARSENIDE AND ORGANO-SILICATE COATINGS AND INFLUENCE OF THAT COATING UPON THE REVERSE CURVE OF CURRENT-VOLTAGE CHARACTERISTICS OF POWER DIODES}

Interaction between gallium arsenide and organo-silicate coating by differential thermal analysis and thermal gravimetric analysis has been investigated. It has been slown that the interaction does not take place between gallium arsenide and the components of coating at the working temperature of the gallium -arsenide diode. The reverse curve of the current-voltage characteristics and stability of the gallium arsenide diode coated by different hermetic coatings, has been investigated. It has been shown that organosilicate composition BHT-45/8 and organo-silicate elastic «Лестосил» provide the lowest level of reverse currents and temporal stability of the devices. 